\title{
Selective oxidations of organoboron compounds catalyzed by
}

\section{Baeyer-Villiger monooxygenases}

\section{Patrícia B. Brondani, ${ }^{a}$ Gonzalo de Gonzalo, ${ }^{\mathrm{b}}$ Marco W. Fraaije ${ }^{\mathrm{b}}$ and \\ Leandro H. Andrade ${ }^{\mathrm{a}^{*}}$}

\author{
aUniversidade de São Paulo, Av. Prof. Lineu Prestes 748, SP 05508-900, São Paulo, Brazil. \\ ${ }^{b}$ University of Groningen, Nijenborgh 4, 9747 AG, Groningen, The Netherlands. \\ *e-mail leandroh@iq.usp.br
}

Keywords: Baeyer-Villiger monooxygenases; boron compounds; oxidation reactions.

\section{INTRODUCTION}

BVMOs are known for performing the oxidation of aldehydes and ketones to their corresponding esters, the oxygenation of heteroatoms (sulfur, nitrogen, phosphorus, boron, selenium) and even epoxidation reactions. ${ }^{1,2}$ In this work we have explored BVMOs and organoboron compounds as well as racemic ones as target substrates in BVMOs-catalyzed oxidation reaction.

\section{RESULTS AND DISCUSSION}

Initially, five boron-containing acetophenones (1-5) and hydroxyacetophenones (6 and 7) were selected as substrates (Scheme 1). When PAMO was used as biocatalyst, the boron oxidation was observed for all substrates affording the corresponding phenols. However, the B-V reaction was achieved only for the 4-substituted substrates. The M446G PAMO mutant presented a similar behavior for all substrates. On the other hand, in all HAPMO-catalyzed reactions, both oxidations occurred (boron oxidation and B-V reaction). The CHMO showed a high chemoselectivity, in favor of boron oxidation, but low activity.

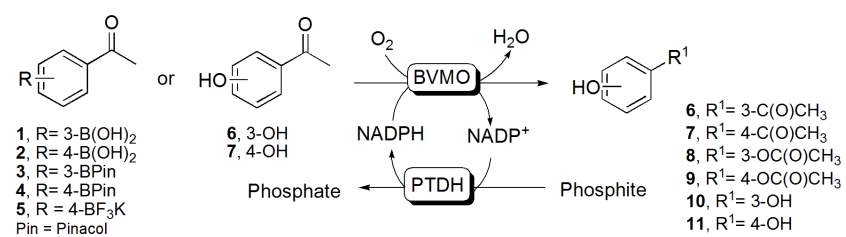

Scheme 1- Oxidation of boron-containing acetophenones catalyzed by BVMOs.

We have also explored the BVMO-catalyzed oxidation of vinyl boron compounds 12-17 (Scheme 2). It was observed that no epoxidation was achieved for any of the substrates and no reaction was observed for compounds 12-14. Nevertheless, only for compounds $\mathbf{1 5 - 1 7}$ the boron oxidation was observed.

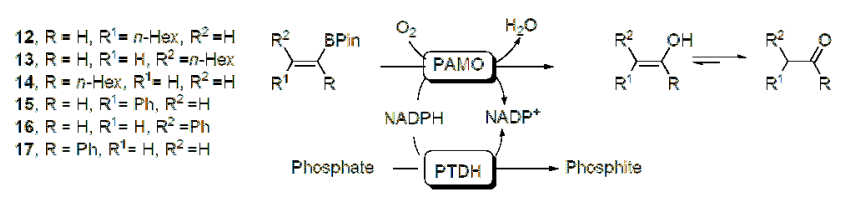

Scheme 2- Oxidation of vinyl boron compounds 12-17 catalyzed by BVMOs.

We also decided to evaluate the enzymatic kinetic resolution of chiral boron-compounds (23 and 24) catalyzed by PAMO (Scheme 3). After $24 \mathrm{~h}$ no reaction was observed for compound 23. However, the enzymatic oxidation of $\mathbf{2 4}$ showed excellent results in which the $(S)$-borane was oxidized to the corresponding $(S)$-alcohol $(\mathrm{ee}=91 \%)$ in $5 \mathrm{~h}$ and $\mathrm{pH}=7.5$ (conv. $=49 \%$ ).

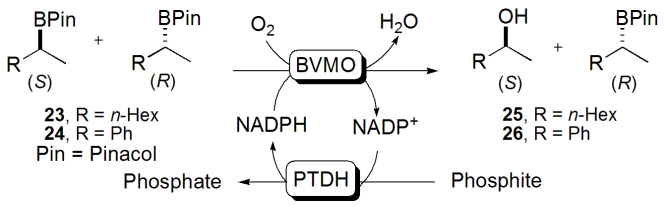

Scheme 3- Kinetic resolution of chiral boron-compounds catalyzed by PAMO.

\section{CONCLUSION}

We have found that the boron oxidation catalyzed by the studied BVMOs occurs rather than the BaeyerVilliger reaction or the epoxidation process. This study also revealed that PAMO is very well suited to perform enantioselective boron oxidations.

\section{ACKNOWLEDGEMENTS}

CNPq, CAPES, FAPESP and EU-FP7 Oxygreen project for financial support.

\section{REFERENCES}

1 a)Torres Pazmiño, D. E.; Dudek, H.; Fraaije, M. W.; Curr. Opin. Chem. Biol. 2010, 14, 138. b) Nolan, L. C.; O'Connor, K. E. Biotechnol. Lett. 2008 30, 1879 c) Van Berkel, W. J. H.; Kamerbeek, N. M.; Fraaije, M. W. J. Biotechnol. 2006, 124, 670. ${ }^{2}$ a) Colonna, S.; Gaggero,N.; Carrea, G. Ottolina, P.; Pasta,P.; Zambianchi, F. Tetrahedron: Lett. 2002, 43, 1797. b) Branchaud, B. P.; Walsh, C. T. J. Am. Chem. Soc. 1985, 107, 2153.

${ }^{3}$ Patti, A.; Pedotti, S.; Sanfilippo,C. Chirality 2007, 19, 344. 